\title{
Simultaneous inhibition of Vps34 kinase would enhance PI3Kס inhibitor cytotoxicity in the B-cell malignancies
}

\author{
Xiaochuan Liu ${ }^{1,2, *}$, Aoli Wang ${ }^{2,3, *}$, Xiaofei Liang ${ }^{2,4, *}$, Juanjuan Liu ${ }^{2,3, *}$, Fengming \\ Zou $^{2,4, *}$, Cheng Chen ${ }^{2,4, *}$, Zheng Zhao ${ }^{2,4}$, Yuanxin Deng ${ }^{2,3}$, Hong Wu ${ }^{2,3}$, Ziping Qi ${ }^{2,4}$, \\ Beilei Wang ${ }^{2,4}$, Li Wang ${ }^{2,4}$, Feiyang Liu ${ }^{2,3}$, Yunhe $X u^{1}$, Wenchao Wang ${ }^{2,4}$, Stacey $M$. \\ Fernandes $^{5}$, Richard M. Stone ${ }^{5}$, Ilene A. Galinsky ${ }^{5}$, Jennifer R. Brown ${ }^{5}$, Teckpeng \\ Loh $^{1}$, James. D. Griffin ${ }^{5}$, Shanchun Zhang ${ }^{4,6}$, Ellen L. Weisberg ${ }^{5}$, Xin Zhang ${ }^{2}$, Jing \\ Liu ${ }^{2,4}$, Qingsong Liu ${ }^{2,3,7}$ \\ ${ }^{1}$ Department of Chemistry, University of Science and Technology of China, Anhui, Hefei, 230036, P. R. China \\ ${ }^{2}$ High Magnetic Field Laboratory, Chinese Academy of Sciences, Hefei, 230031, Anhui, P. R. China \\ ${ }^{3}$ University of Science and Technology of China, Anhui, Hefei, 230036, P. R. China \\ ${ }^{4}$ CHMFL-HCMTC Target Therapy Joint Laboratory, Hefei, 230031, Anhui, P. R. China \\ ${ }^{5}$ Department of Medical Oncology, Dana-Farber Cancer Institute, Harvard Medical School, Boston, MA 02115, USA \\ ${ }^{6}$ Hefei Cosource Medicine Technology Co. LTD. Hefei, 230031, Anhui, P.R.China \\ ${ }^{7}$ Hefei Science Center, Chinese Academy of Sciences, Hefei, 230031, Anhui, P. R. China \\ * These authors have contributed equally to this work \\ Correspondence to: Ellen L. Weisberg, email: Ellen_weisberg@dfci.harvard.edu \\ Xin Zhang, email: xinzhang@hmfl.ac.cn \\ Jing Liu, email: jingliu@hmfl.ac.cn \\ Qingsong Liv, email: qsliu97@hmfl.ac.cn
}

Keywords: PI3KS, Vps34, combination, chronic lymphatic leukemia, acute myeloid leukemia

Published: July 18, 2016

\section{ABSTRACT}

PI3Kठ has been found to be over-expressed in B-Cell-related malignancies. Despite the clinical success of the first selective PI3Kס inhibitor, CAL-101, inhibition of PI3Kס itself did not show too much cytotoxic efficacy against cancer cells. One possible reason is that PI3Kס inhibition induced autophagy that protects the cells from death. Since class III PI3K isoform PIK3C3/Vps34 participates in autophagy initiation and progression, we predicted that a PI3Kס and Vps34 dual inhibitor might improve the anti-proliferative activity observed for PI3Kס-targeted inhibitors. We discovered a highly potent ATP-competitive PI3Kס/Vps34 dual inhibitor, PI3KD/V-IN-01, which displayed 10-1500 fold selectivity over other PI3K isoforms and did not inhibit any other kinases in the kinome. In cells, PI3KD/V-IN-01 showed 30-300 fold selectivity between PI3Kס and other class I PI3K isoforms. PI3KD/V-IN-01 exhibited better antiproliferative activity against AML, CLL and Burkitt lymphoma cell lines than known selective PI3Kס and Vps34 inhibitors. Interestingly, we observed FLT3-ITD AML cells are more sensitive to PI3KD/V-IN-01 than the FLT3 wt expressing cells. In AML cell inoculated xenograft mouse model, PI3KD/V-IN-01 exhibited dose-dependent antitumor growth efficacies. These results suggest that dual inhibition of PI3Kס and Vps34 might be a useful approach to improve the PI3Kס inhibitor's anti-tumor efficacy.

\section{INTRODUCTION}

PI3K $\delta$ belongs to the Class I PI3K family, which also consists of PI3K $\alpha, \beta$ and $\gamma$, and is predominantly expressed in leukocytes.[1] Deregulation of PI3K $\delta$, for example over-expression, has been found in B-cell malignancies such as Chronic Lymphatic Leukemia (CLL), indolent non-Hodgkin Lymphoma and Acute Myeloid Leukemia (AML).[2, 3] Constitutive activation of B-cell receptor (BCR) or proliferation and survival factors present in bone marrow and lymph node microenvironment may activate the $\mathrm{PI} 3 \mathrm{~K} \delta$-mediated signaling pathway, which will lead 
to aberrant cell proliferation, survival and differentiation. [4] The seminal discovery of the PI3K $\delta$ selective inhibitor, CAL-101 (Idelalisib), and its successful clinical application toward CLL and Indolent NHL, have validated PI3K $\delta$ as a drug discovery target.[5] However, both preclinical and clinical tests have shown that inhibition of PI3K $\delta$ alone only exerted limited cytotoxicity against the transformed cells directly, but rather inhibited cell survival by interfering with the microenvironment, such as by blocking the cytokines TNF- $\alpha$, IL- 6 , etc to prevent the leukemic cells from circulating back to the lymph nodes and bone marrow for the further proliferation.[6] In order to improve clinical efficacy, various combination therapies have been suggested such as those involving in chemotherapy, and other signaling pathway inhibitors including MEK, BRAF, MYC, PARP, BCL-2 and autophagy.[7] Among them, the autophagy signaling pathway has attracted special attention since inhibition of the PI3K/AKT/mTOR signaling pathway is known to induce autophagy, which could provide a prosurvival mechanism for the cancer cells to escape apoptosis. [8] In addition, there is evidence that treatment of CLL cells with CAL-101 induces autophagy.[9] Therefore, simultaneous inhibition of $\mathrm{PI} 3 \mathrm{~K} \delta$ and autophagy might enhance the clinical efficacy of PI3K $\delta$ inhibitors.

Vps34 belongs to Class III PI3K family and has been shown to be essential for autophagy initiation and progression. It is thought that VPS34 kinase can synthesize and deposit the phophatidylinositol-3-phosphate (PtdIns(3)P) on the autophagosome formation site, and hence inhibition of the Vps34 would block the autophagosome formation process and result in prevention of autophagy.[10] Recently, the discovery of several selective Vps34 inhibitors, such as Vps34-IN-1, PIK-III, SAR405, has clearly proven this. [11-14] In addition, the combination of the Vps34 specific inhibitor, SAR405, with the mTOR inhibitor, everolimus, which can induce the autophagy, has been shown to be synergistic in renal cell carcinoma cell lines.[12]

Given the possible protective effects of autophagy induced by $\mathrm{PI} 3 \mathrm{~K} \delta$ inhibition and the structural similarity between PI3K $\delta$ (Class I PI3K) and Vps34 (Class III PI3K), we postulated that development of a selective PI3K $\delta$ and Vps34 dual inhibitor might enhance the cytotoxic effect of PI3K $\delta$ inhibition on B-cell malignances, such as CLL and AML. This led to the discovery of a highly selective $\mathrm{PI} 3 \mathrm{~K} \delta / \mathrm{Vps} 34$ dual inhibitor, PI3KD/V-IN-01, which displays superior anti-proliferative activity against B-Cell malignant cells in vitro and in vivo.

\section{RESULTS}

\section{$\mathrm{PI3KD/V-IN-01} \mathrm{is} \mathrm{a} \mathrm{highly} \mathrm{selective} \mathrm{and} \mathrm{potent}$ PI3Kס/Vps34 dual inhibitor}

A focused medicinal chemistry approach based on an aminothiazole scaffold led to a highly potent $\mathrm{PI} 3 \mathrm{~K} \delta / \mathrm{Vps} 34$ dual inhibitor, PI3KD/V-IN-01. (chemical structure shown in Figure 1A) In the ADP-Glo ${ }^{\mathrm{TM}}$ biochemical assay with purified PI3K isoform proteins, PI3KD/V-IN-01 displayed an $\mathrm{IC}_{50}$ of $6 \mathrm{nM}$ against PI3K $\delta$ and $19 \mathrm{nM}$ against VPS34. (Figure 1B) Among other PI3Ks, it exhibited an $\mathrm{IC}_{50}$ of $64 \mathrm{nM}$ against Class I PI3K PI3K $\alpha, 111 \mathrm{nM}$ against $\mathrm{PI} 3 \mathrm{~K} \beta, 119 \mathrm{nM}$ against PI3K $\gamma$. In contrast, the drug showed little activity against Class II PI3Ks and PI4K $\alpha / \beta$. A kinetic study with varied ATP concentrations showed that PI3KD/V-IN-01 was an ATP competitive inhibitor against both $\mathrm{PI} 3 \mathrm{~K} \delta$ and Vps34. (Supplemental Figure 1A, 1B) Further characterization of PI3KD/V-IN-01 in the cellular context for the class I PI3Ks demonstrated that it potently inhibited anti-IgM- stimulated PI3K $\delta$ activity in Raji cells with an $\mathrm{EC}_{50}$ of $11 \mathrm{nM}$, however exhibited far less activity against PI3K $\alpha\left(\mathrm{EC}_{50}: 2966 \mathrm{nM}\right), \mathrm{PI} 3 \mathrm{~K} \beta$ $\left(\mathrm{EC}_{50}:>3000 \mathrm{nM}\right)$ and PI3K $\gamma\left(\mathrm{EC}_{50}: 186 \mathrm{nM}\right)$. (Figure 1C and Table 1) Further characterization of the selectivity profile in the DiscoveRx's KinomeScan ${ }^{\mathrm{TM}}$ platform showed that PI3KD/V-IN-01 $(1 \mu \mathrm{M})$ is highly selective and did not potently bind to any of other protein kinases (S score $(5)=0.00)$. (Figure 1D) In addition to Class I PI3K family kinases, PI3KD/V-IN-01 also strongly bound to the structurally similar mTOR kinase (\% control number $=0$ ). However, the activity-based in vitro IP kinase assay demonstrated only modest inhibition of mTORC1 kinase by PI3KD/V-IN-01 ( $\mathrm{EC}_{50}$ of $\left.1700 \mathrm{nM}\right)$, which is much less potent than activity displayed against $\mathrm{PI} 3 \mathrm{~K} \delta$ and vps 34 kinases. (Supplemental Figure 3) In HeLa cells, PI3KD/VIN-01 effectively prevented LC3BII accumulation in the presence of EBSS (Earle's balanced salt solution) and HCQ (hydrochloroquine) with an $\mathrm{EC}_{50}$ of $413 \mathrm{nM}$. (Figure 1E) In addition, an immunofluorescence experiment showed that PI3KD/V-IN-01 increased LC3B puncta in HeLa cells in a dose-dependent way, which was similar to the Vps34 specific inhibitor Vps34-IN-1, but not for the PI3K $\delta$ inhibitor CAL-101 or pan-PI3K inhibitor GDC0941. (Figure 1F and Supplemental Figure 2) This is not surprising as HeLa cells express Vps34 but not PI3K $\delta$. In accordance with the established function of Vps34 in membrane trafficking $[16,17]$, the lysosome marker LAMP1 localization was affected by PI3KD/V-IN-01 and Vps34-IN-1, however not GDC-0941 or CAL-101. (Figure 1F) These biochemical and cellular data demonstrate that $\mathrm{PI} 3 \mathrm{KD} / \mathrm{V}-\mathrm{IN}-01$ was a highly potent and selective PI3K $\delta$ / Vps34 dual inhibitor.

\section{PI3KD/V-IN-01 exhibits anti-proliferative activity against B-cell-related cancer cell lines}

We next tested PI3KD/V-IN-01 in a panel of B-cellrelated cancer cell lines, including AML, CLL, Burkitt lymphoma and B-cell lymphoma. (Table 2) PI3KD/VIN-01 was more potent than the selective PI3K $\delta$ inhibitor, CAL-101, and selective Vps34 inhibitor, Vps34-IN-1, against most of the cell lines, however less potent than the pan-PI3K inhibitor, GDC-0941. Specifically, CAL-101 did 
not effectively inhibit the majority of the cell lines tested, except OCI-AML-3 (AML, GI50: $2.4 \mu \mathrm{M}$ ). Interestingly, Vps34-IN-1 itself showed micro molar potencies against most of cell lines, including two CLL cell lines (HS505T and MEC-1), the latter of which poorly responded to CAL-101, GDC-0941 and PI3KD/V-IN-01 (GI50: >10 $\mu \mathrm{M})$. What is worthy to note is that PI3KD/V-IN-01 was most potent against several FLT3-ITD-positive cell lines
A.<smiles>Cc1nc(NC(=O)CN)sc1-c1cnc(Cl)c(NS(=O)(=O)c2ccc(C(C)(C)C)cc2)c1</smiles>

PI3KD/V-IN-01
B.

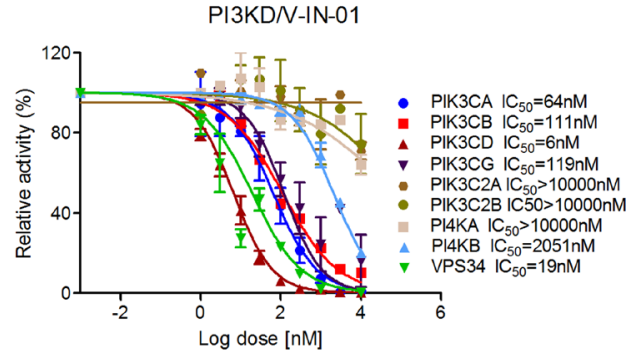

c.
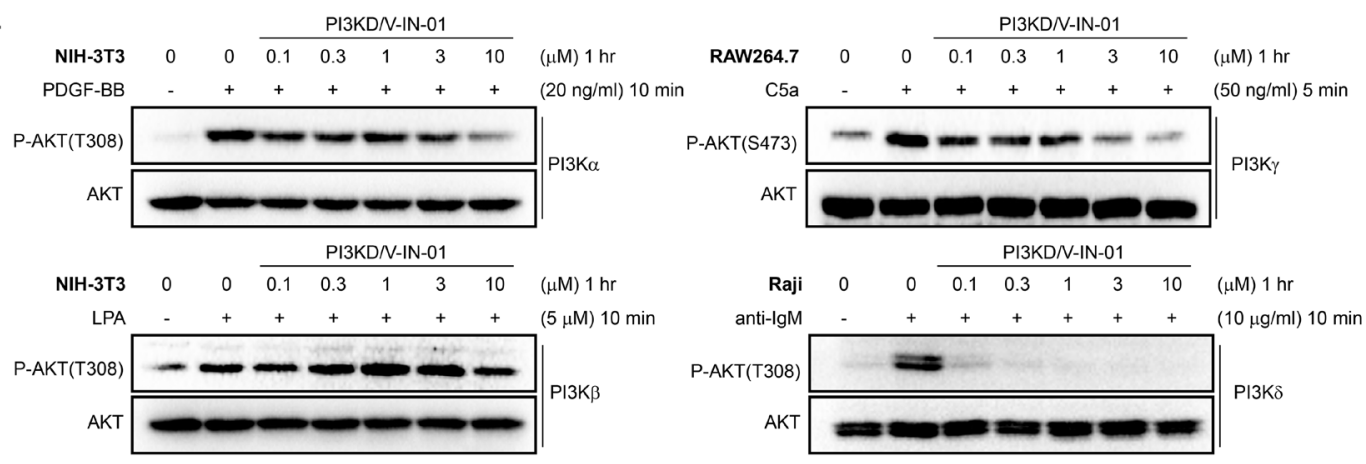

D.

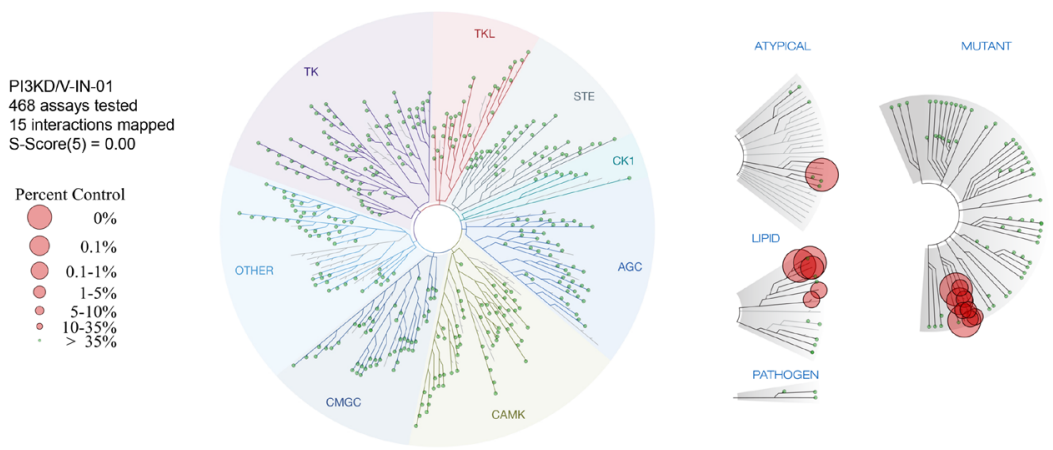

E.

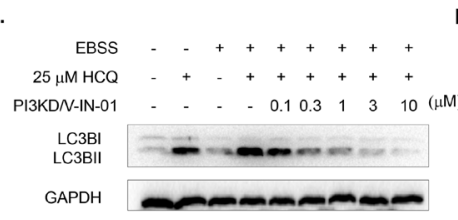

F.

control PI3KD/N-IN-01 VPS34-IN-1 GDC0941 CAL101
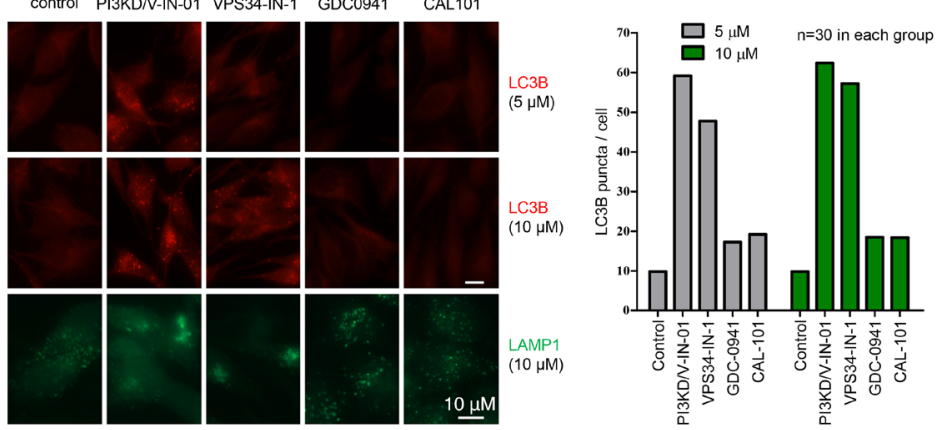

Figure 1: Biochemical and pharmacological characterization of PI3KD/V-IN-01. A. Chemical structure of PI3KD/V-IN-01. B. ADP-Glo ${ }^{\mathrm{TM}}$ Biochemical IC50 determination of PI3KD/V-IN-01 against a panel of PI3K-related kinases. C. Determination of the inhibitory effect of PI3KD/V-IN-01 against class I PI3Ks in the cellular context. Specifically, PI3K $\alpha$ in NIH-3T3 cells with PDGF-BB stimulation; PI3K $\beta$ in NIH-3T3 cells with LPA stimulation; PI3K $\gamma$ in RAW264.7 cells with C5a stimulation; PI3K $\delta$ in Raji cells with antiIgM stimulation. D. Selectivity profile of PI3KD/V-IN-01 in the DiscoveRx's KinomeScan ${ }^{\mathrm{TM}}$ platform. E. Effect of PI3KD/V-IN-01 on autophagy in HeLa cells using co-culture of EBSS and HCQ $(25 \mu \mathrm{M})$ and investigating LC3BII expression. F. Immuno-fluorescent imaging analysis of the effect of PI3K inhibitors on LC3BII expression in HeLa cells and of LAMP1 expression in HeLa cells treated with PI3K inhibitors. 
Table 1: Quantification of PI3KD/V-IN-01 EC50 against class I PI3Ks

\begin{tabular}{|c|c|c|c|c|}
\hline Cellular EC50 (nM) & PI3Ka & PI3K $\beta$ & PI3K $\gamma$ & PI3Kס \\
\hline PI3KD/V-IN-01 & 2966 & $>3000$ & 186 & 11 \\
\hline
\end{tabular}

Table 2: PI3K inhibitor anti-proliferative effect against a panel of B-cell related cancer cell lines

\begin{tabular}{|c|c|c|c|c|c|}
\hline $\mathrm{GI}_{50}(\mu \mathrm{M})$ & Cell type & CAL-101 & GDC-0941 & PI3KD/V-IN-01 & VPS34-IN-1 \\
\hline Primary target & I & PI3Kס & pan-PI3Ks & PI3Kס/Vps34 & Vps34 \\
\hline U937 & AML(FLT3wt) & $>10$ & 1.6 & 2.2 & 2.1 \\
\hline CMK & AML(FLT3wt) & $>10$ & 0.3 & 2 & 5.9 \\
\hline NB4 & AML-3 (FLT3wt) & $>10$ & 1 & 1.4 & 6.4 \\
\hline HL-60 & AML (FLT3 wt) & $>10$ & 0.16 & 2.7 & 0.51 \\
\hline OCI-AML-3 & AML(FLT3wt) & 2.4 & 0.73 & 2.4 & 3.6 \\
\hline OCI-AML-2 & AML(FLT3wt) & $>10$ & 2 & 1 & 6.6 \\
\hline NOMO-1 & AML (FLT3wt) & $>10$ & 1 & 2.3 & 1.8 \\
\hline SKM-1 & AML(FLT3wt) & $>10$ & 0.3 & 1 & 6.4 \\
\hline MOLM-14 & AML (FLT3-ITD) & 7.8 & 0.3 & 0.51 & 7.8 \\
\hline MOLM-13 & AML(FLT3-ITD) & $>10$ & 0.15 & 0.28 & 0.7 \\
\hline MV4-11 & AML (FLT3-ITD) & $>10$ & 1.4 & 0.78 & 2.4 \\
\hline HEL & AML(FLT3wt) & $>10$ & $>10$ & $>10$ & 1.7 \\
\hline HT & B-cell lymphoma & $>10$ & 0.5 & 1.9 & 1.4 \\
\hline Ramos & Burrkit lymphoma & $>10$ & 2.1 & 5.4 & 3.3 \\
\hline Namalwa & Burrkit lymphoma & $>10$ & 0.39 & 1.3 & 8.1 \\
\hline MEC-2 & CLL & $>10$ & $>10$ & 2.4 & 3.1 \\
\hline Hs 505T & CLL & $>10$ & $>10$ & $>10$ & 3 \\
\hline MEC-1 & CLL & $>10$ & $>10$ & $>10$ & 3.7 \\
\hline
\end{tabular}

(GI50 below 1 $\mu \mathrm{M}$ ), including MV4-11, MOLM-13 and MOLM-14. PI3KD/V-IN-01 inhibited colony formation of OCI-AML-2 (AML, EC ${ }_{50} 145$ nM), OCI-AML-3(AML, $\left.\mathrm{EC}_{50}: 1001 \mathrm{nM}\right), \mathrm{MV} 4-11\left(\mathrm{AML}, \mathrm{EC}_{50}: 124 \mathrm{nM}\right)$ and MEC-2 (CLL, EC 50 : 1579 nM). (Supplemental Figure 4)

\section{PI3KD/V-IN-01 suppresses the PI3K $\delta$-mediated signaling pathway, interferes with autophagy and arrests cell cycle progression in AML and CLL cell lines}

We next examined the effect of PI3KD/V-IN-01 on the PI3K $\delta$-mediated signaling pathway in OCI-AML2(AML), OCI-AML-3(AML), MV4-11(AML), and MEC2 (CLL) cell lines. (Figure 2A) For all four cell lines, PI3KD/V-IN-01 treatment led to inhibition of pAKT(T308, S473) and downstream pFOXO1, pPRAS40 and pS6K. Phosphorylation of 4EBP1 was not inhibited in any of the cell lines, which supports the notion that PI3KD/V-
IN-01 does not bear activity against mTOR kinase: this is in accordance with results of the in vitro IP kinase assay. Activity of the downstream AKT kinase mediator, GSK3 $\beta$, and downstream transcription regulator, $\mathrm{NF} \kappa \mathrm{B}$, were not affected in any of the cell lines. What is noteworthy is that in MEC-2 cells, pERK was significantly inhibited by PI3KD/ V-IN-01, GDC-0941 and CAL-101, but this phenomenon was not observed in OCI-AML-2, OCI-AML-3 and MV4-11 cells. These results demonstrate that $\mathrm{PI} 3 \mathrm{~K} \delta$ is effectively inhibited in the cellular context, however differential responsiveness of certain signaling molecules to the inhibitors tested suggest that these cells might rely on different genetic/signaling network backgrounds.

We next examined the effect of PI3KD/V-IN-01 on induction of apoptosis. Interestingly, only for MV411 was apparent PARP cleavage observed, which clearly suggests drug-induced apoptosis of this line. (Figure 2B) For OCI-AML-2 and MEC-2, there was only a modest induction of apoptosis (evident at $3 \mu \mathrm{M}$ to 10 
A.
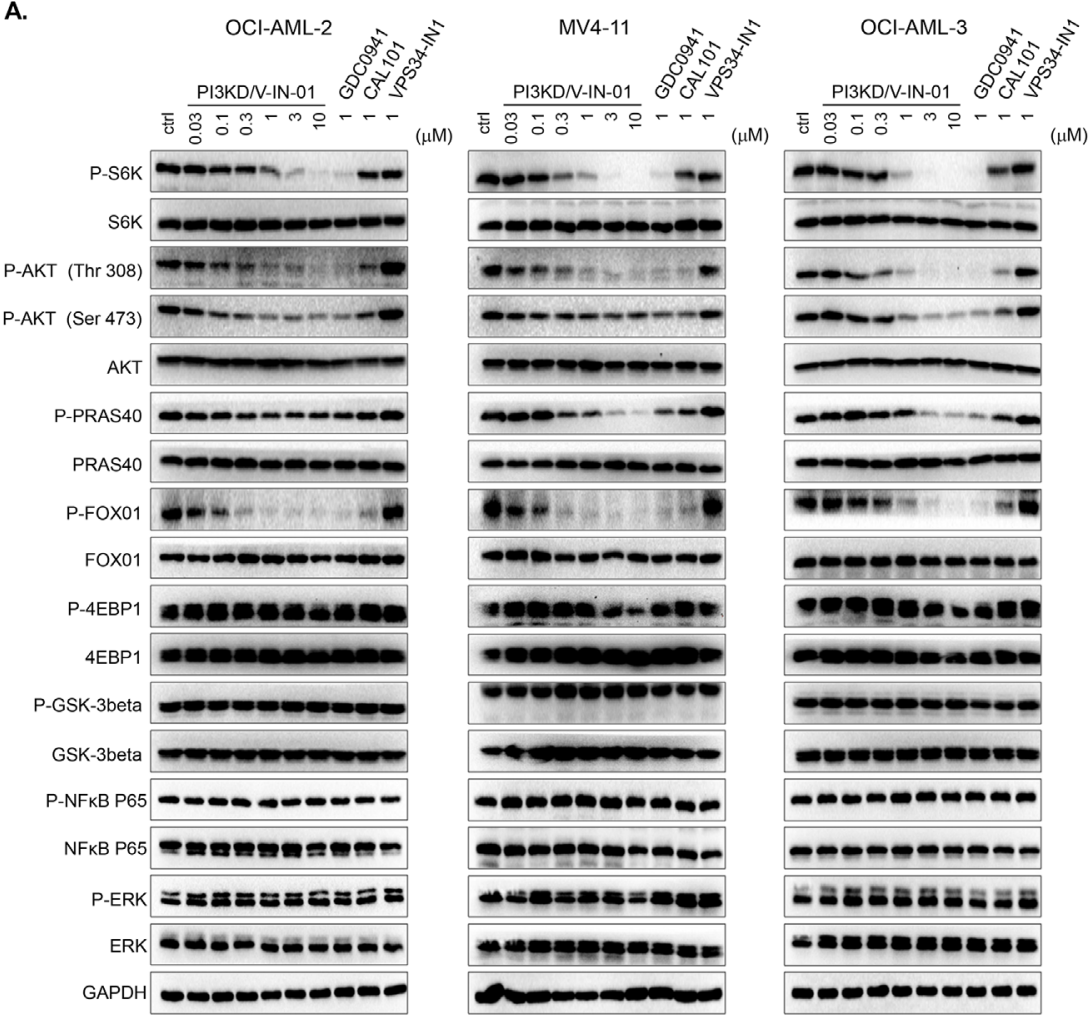

(4)

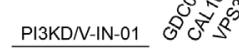

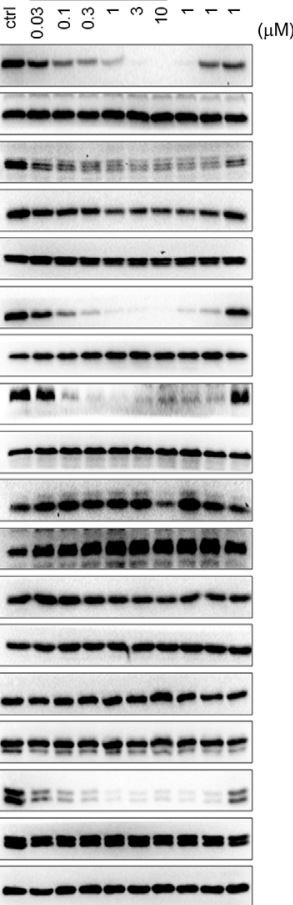

B.
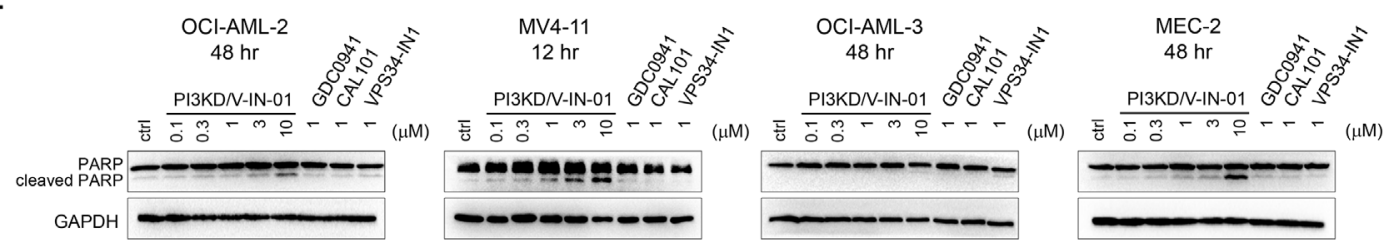

c.
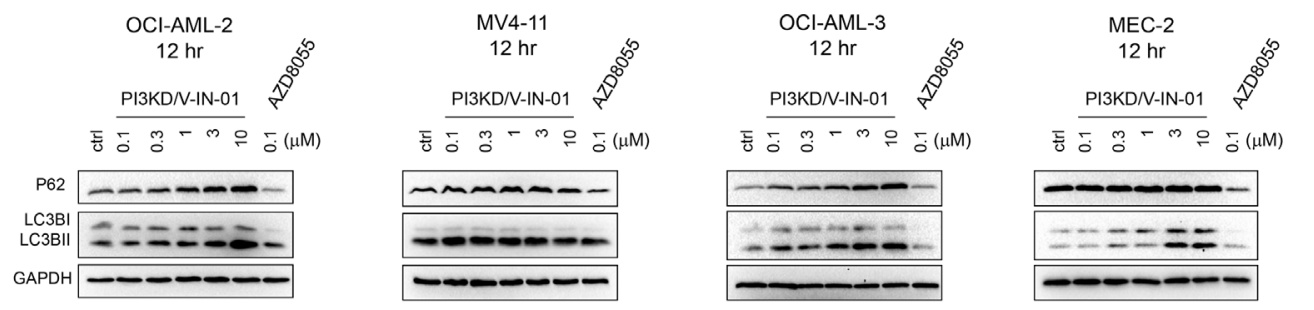

D.

OCI-AML-2

MV4-11

OCI-AML-3

MEC-2
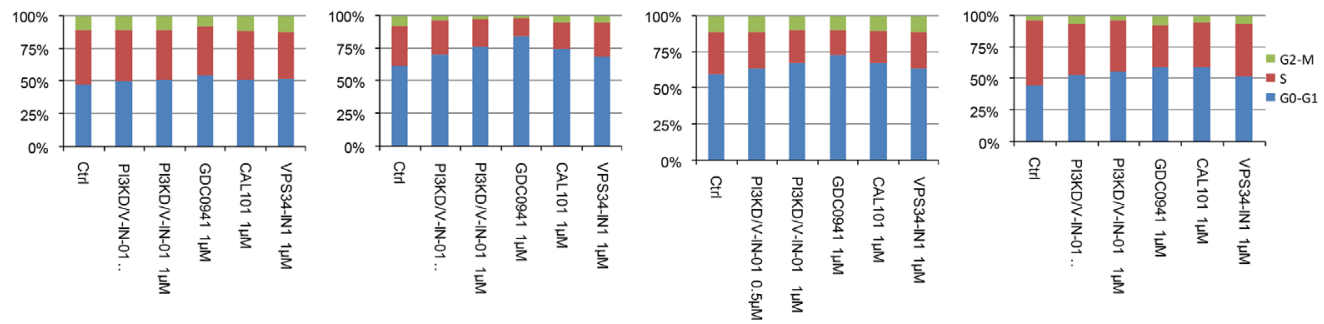

Figure 2: Effect of PI3KD/V-IN-01 on cellular signaling, cell cycle progression, and autophagy. A. Effect of $\mathrm{PI} 3 \mathrm{KD} / \mathrm{V}$ IN-01 on PI3K $\delta$ - mediated signaling pathways in OCI-AML-2 (AML), MV4-11 (AML), OCI-AML-3(AML) and MEC-2 (CLL) cell lines. B. Apoptotic effect of PI3KD/V-IN-01 in OCI-AML-2, MV4-11, OCI-AML-3 and MEC-2 cells. C. Autophagy interruption effect of PI3KD/V-IN-01 in OCI-AML-2, MV4-11, OCI-AML-3 and MEC-2 cells. D. Cell cycle progression effect of PI3KD/V-IN-01 in OCIAML-2, MV4-11, OCI-AML-3 and MEC-2 cells. 
$\mu \mathrm{M})$, and for OCI-AML-3, no apoptosis was observed, even at concentrations up to $10 \mu \mathrm{M}$. Of relevance, a concentration-dependent increase in levels of the autophagy markers, LC3BII and p62, was observed in OCI-AML-2, OCI-AML-3 and MEC-2. (Figure 2C) However, this phenomenon was not observed for MV411 cell line. Cell cycle analysis showed that after $48 \mathrm{~h}$ treatment with PI3KD/V-IN-01, MV4-11, OCI-AML-3 and MEC-2 cells could be arrested in the G0/G1 phase, while there was no apparent cell cycle inhibition observed for drug-treated OCI-AML-2 cells. (Figure 2D)

\section{Combination of CAL-101 and Vps34-IN-1 recapitulates the dual inhibitory effect of $\mathrm{PI3KD} /$ V-IN-01}

We next investigated whether or not the combination of the selective PI3K $\delta$ inhibitor, CAL-101, and selective Vps34 inhibitor, VPS34-IN-1, was able to mimic the anti-proliferative effect of dual PI3K $\delta / \mathrm{Vps} 34$ inhibitor, PI3KD/V-IN-01. The results suggest that for the OCI-AML-2 cells (AML), $1.1 \mu \mathrm{M}$ Vps34-IN-1 (treatment with which leads to $82.8 \%$ inhibition of cell growth/viability) and $10 \mu \mathrm{M}$ of CAL-101 (treatment with which leads to $76.9 \%$ inhibition of cell growth/viability) would together lead to $37.2 \%$ inhibition. (Figure 3A) For MV4-11 cells (AML), $3.3 \mu \mathrm{M}$ of Vps34-IN-1(treatment with which leads to $43.5 \%$ inhibition of cell growth/

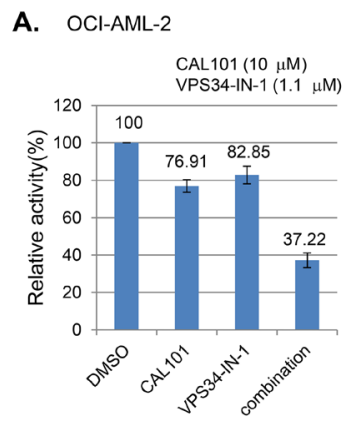

B. MV4-11
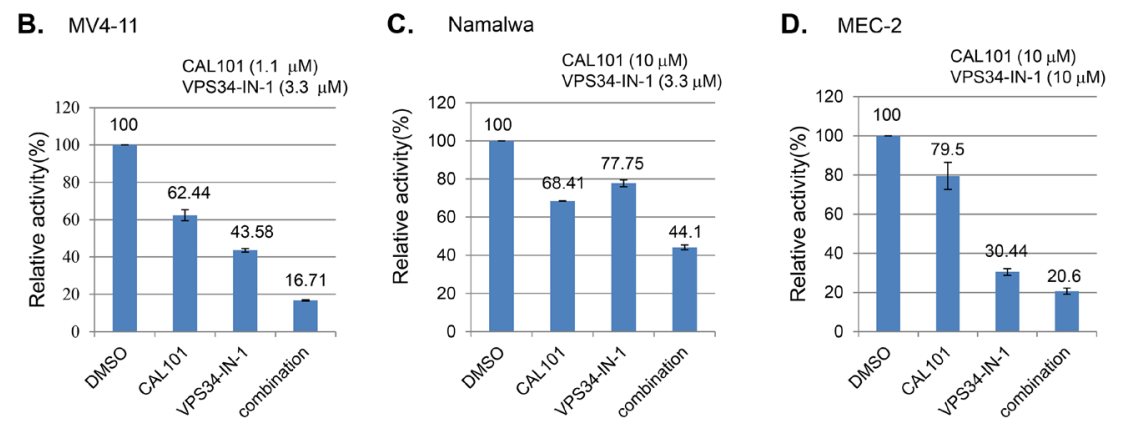

E.
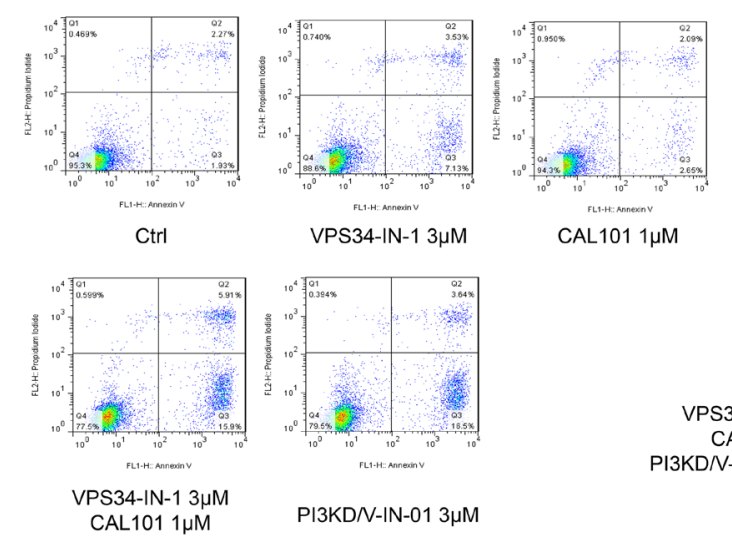

viability) and $1.1 \mu \mathrm{M}$ of CAL-101 (treatment with which leads to $62.4 \%$ inhibition of cell growth/viability) could together synergistically lead to $16.7 \%$ inhibition. (Figure 3B) Similarly, in Namalwa (Burrkit lymphoma) and MEC-2 cells (CLL), $10 \mu \mathrm{M}$ of Vps34-IN-1 and 3.3 and $10 \mu \mathrm{M}$ of CAL-101, respectively, together synergistically caused significant inhibition of cell growth/viability. (Figure 3C and 3D) We also investigated the extent of drug-induced apoptosis following drug combination treatment in MV4-11 cells, as PI3KD/V-IN-01 was observed to lead to substantial induction of apoptosis. (Figure 2B) The results suggest that $1 \mu \mathrm{M}$ of CAL-101 and $3 \mu \mathrm{M}$ of Vps34-IN-1 significantly increased the percentage of cells undergoing apoptotic cell death, similar to what was observed with $3 \mu \mathrm{M}$ of PI3KD/VIN-01. (Figure 3E)

\section{PI3KD/V-IN-01 inhibited growth of CLL patient primary cells and $A M L$ primagraft cells and displayed anti-tumor activity in an MV4-11- inoculated xenograft mouse model}

PI3KD/V-IN-01 inhibited the growth of primary CLL cells, with approximately $50 \%$ of cell proliferation inhibited at $1 \mu \mathrm{M}$ following 72 hours. (Figure 4A and supplemental Table 1 for the patient information) In addition, PI3KD/V-IN-01 inhibited the growth of AML primagraft cells ex vivo following 72 hours. Of interest,
C. Namalwa

Figure 3: Combinatorial effect of PI3Kס selective inhibitor CAL-101 and Vps34 selective inhibitor VPS34-IN-1. Combination of CAL-101 and Vps34-IN-1 against OCI-AML-2 A., MV4-11 B., Namalwa C., and MEC-2 D. E. FACS PI/Annexin V double staining analysis showing effect of the drug combination on induction of apoptosis. 
A.

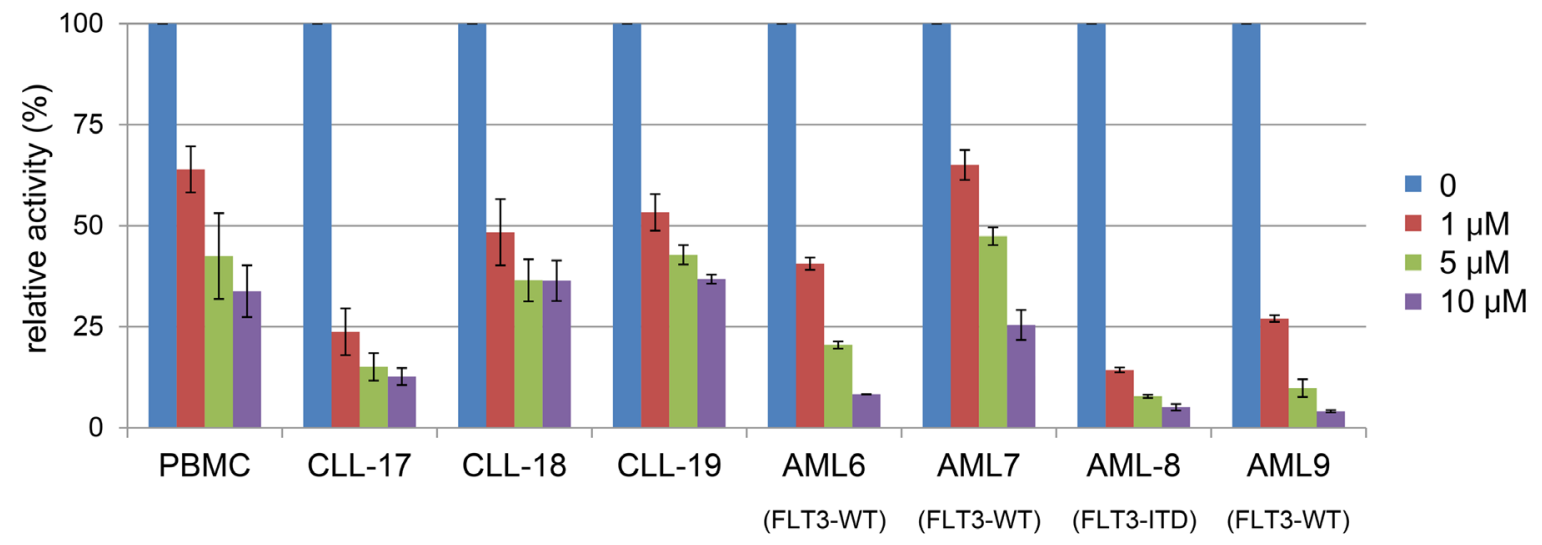

B.

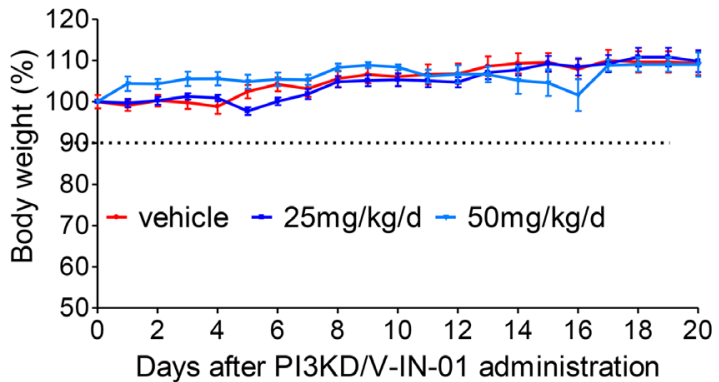

C.

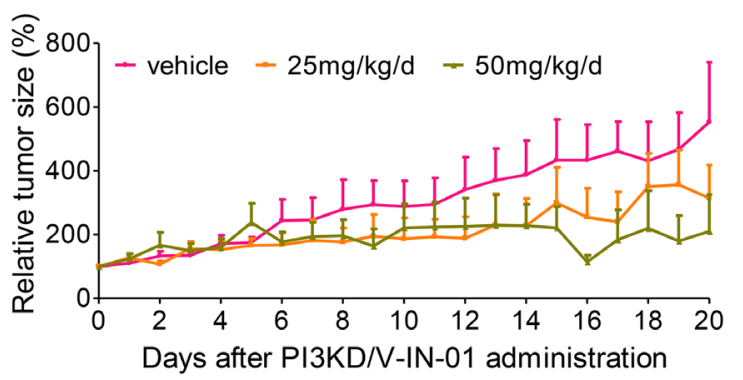

D.
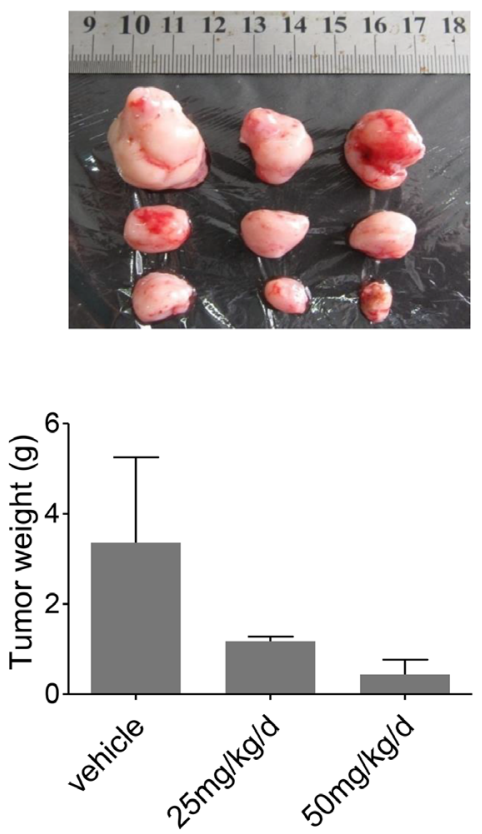

E.
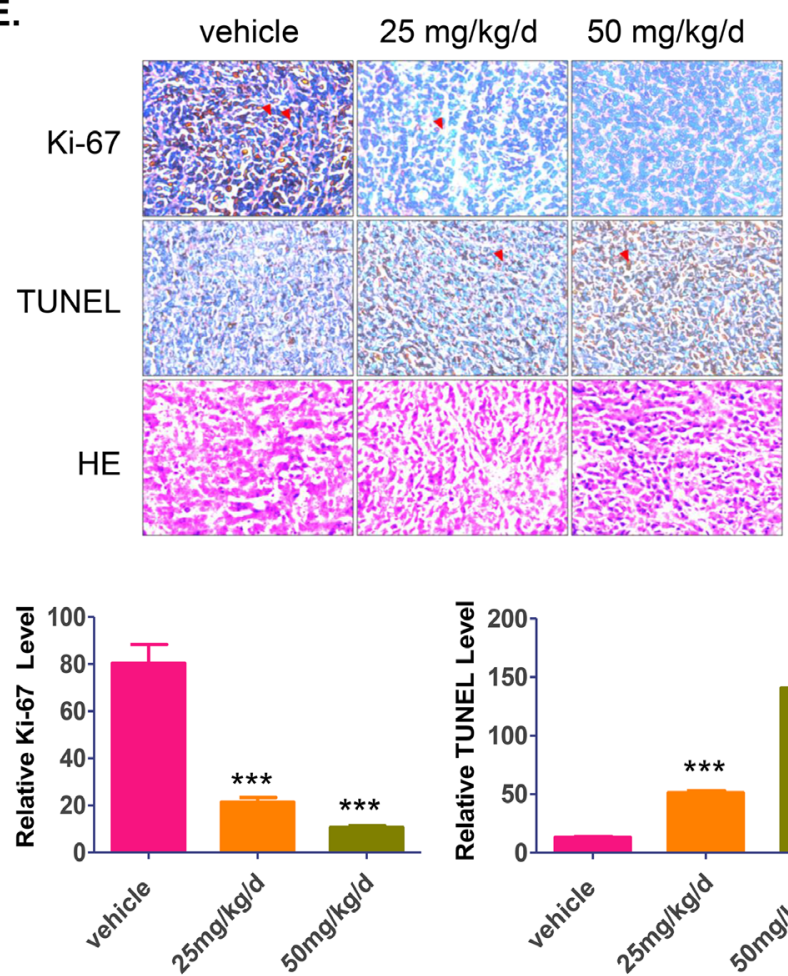

Figure 4: Effect of PI3KD/V-IN-01 on CLL and AML patient primary cells and an MV4-11 cell-inoculated xenograft mouse model. A. Anti-proliferative effect of PI3KD/V-IN-01 on patient CLL primary cells and AML primagrafts cells. B. The effect of PI3KD/V-IN-01 in an MV4-11-inoculated mouse xenograft model: measurement of body weight. C, D. The anti-tumor effect of PI3KD/VIN-01 in an MV4-11- inoculated mouse xenograft model. E. Immunohistochemistry staining of Ki67, TUNEL and HE to look at the tumor cell proliferation and apoptosis in the tumor tissues. 
FLT3-ITD positive primary AML cells were observed to be particularly sensitive to PI3KD/V-IN-01, with over $85 \%$ inhibition observed at $1 \mu \mathrm{M}$. (Figure $4 \mathrm{~A}$ )

Given that FLT3-ITD-positive MV4-11 cells and FLT3-ITD-positive primary AML cells were observed to be especially sensitive to PI3KD/V-IN-01 (see Table 1), we decided to investigate the in vivo effects of PI3KD/V-IN-01 using an in vivo model of mutant FLT3positive leukemia. A dose of $50 \mathrm{mg} / \mathrm{kg} /$ day administered intraperitoneal almost completely suppressed the in vivo growth of inoculated MV4-11 cells with a TGI (Tumor growth inhibition) of $86.8 \%$, with no apparent effects on body weight, suggesting a lack of toxicity. (Figure 4B, 4C and 4D) Immunohistochemistry study showed that the cell proliferation was dose-dependently inhibited (Ki67 stain) and apoptosis was dose-dependently increased (TUNEL stain). (Figure 4E)

\section{DISCUSSION}

The seminal discovery of the first highly selective PI3K $\delta$ inhibitor, CAL-101, has greatly advanced progress in treatment of B-cell related malignancies. However, despite the promising clinical success with CAL-101 as a single agent, cytotoxicity against the cancer cell itself has limited its overall efficacy. Autophagy may be one of the mechanisms whereby cells overcome the activity of PI3K $\delta$ inhibitors such as CAL-101. Here, through the discovery of a highly selective $\mathrm{PI} 3 \mathrm{~K} \delta / \mathrm{Vps} 34$ inhibitor PI3KD/VIN-01, which can efficiently block the PI3K $\delta$ mediated signaling pathway and autophagy, we found that dual inhibition of PI3K $\delta$ and Vps34 greatly enhances the antiproliferative effects of single $\mathrm{PI} 3 \mathrm{~K} \delta$ and $\mathrm{Vps} 34$ inhibitors in B-cell cancers such as AML, CLL, and B-NHL. This dual inhibition can be recapitulated by the combination of PI3K $\delta$ and Vps34 selective inhibitors individually. Our results further prove that autophagy is indeed an important factor leading to protection of leukemic cells from death upon $\mathrm{PI} 3 \mathrm{~K} \delta$ inhibitor treatment, and simultaneous inhibition of both targets potentiates anti-leukemic activity. In addition, given the complexities of drug-drug interactions and increased risk of toxicity resulting from this, discovery of a carefully controlled single agent, multi-targeted drug is preferable.

Interestingly, FLT3-ITD positive cell lines, such as MV4-11, MOLM-13, and MOLM-14, and FLT3-ITD positive primary AML cells are much more sensitive to PI3KD/V-IN-01 inhibition than wt FLT3 AML cell lines and primagrafts. However, this trend was not observed for either of the PI3K $\delta$ selective inhibitor, CAL-101, or the Vps34 selective inhibitor, Vps34-IN-1, or the panPI3K inhibitor GDC-0941. These cells are dependent on FLT3-ITD for growth and did not seem to rely on autophagy for escape from cell death upon PI3K $\delta$ inhibitor treatment. Considering the high selectivity of PI3KD/V-IN-01 revealed in KinomeScan ${ }^{\mathrm{TM}}$ profiling, it is unlikely that the other kinase targets contribute to its efficacy. One possible reason is that $\mathrm{PI} 3 \mathrm{~K} \delta$ is a downstream mediator of FLT3-ITD activation, and dual inhibition of PI3K $\delta$ and Vps34 may lead to enhanced killing of these cells.

In summary, we have discovered a highly selective and potent $\mathrm{PI} 3 \mathrm{~K} \delta / \mathrm{Vps} 34$ dual kinase inhibitor, PI3KD/VIN-01, which exerts better anti-proliferative effects against the majority of B-cell related malignancies that we tested (AML, CLL and B-NHL) as compared to individual targeted $\mathrm{PI} 3 \mathrm{~K} \delta$ and Vps34 inhibitors. PI3KD/V-IN-01 is particularly potent against FLT3-ITD positive AML cells and exhibits significant anti-tumor activity in vivo. PI3KD/ V-IN-01 thus represents a novel and potentially alternative approach to enhance the activity of PI3K $\delta$ inhibitors and warrants further clinical investigation as a therapeutic agent for B-cell malignancies.

\section{MATERIALS AND METHODS}

\section{Reagents}

CAL-101, GDC-0941 and VPS34-IN-1 were purchased from Haoyuan Chemexpress Inc. (Shanghai, China) Recombinant PI3K $\alpha, \mathrm{PI} 3 \mathrm{~K} \delta, \mathrm{PI} 3 \mathrm{~K} \gamma, \mathrm{PI} 3 \mathrm{KC} 2 \alpha$, PI3KC2 $\beta, V p s 34, \mathrm{PI} 4 \mathrm{~K} \alpha, \mathrm{PI} 4 \mathrm{~K} \beta$ and lipid substrates $\mathrm{PI}, \mathrm{PIP}_{2}: \mathrm{PS}$ and PI:PS were purchased from Invitrogen. Recombinant PI3K $\beta$ was from Sigma. The ADP-Glo ${ }^{\mathrm{TM}}$ kinase assay kit was from Promega Corporation.

\section{Cell lines and cell culture}

The human cancer cell lines, SKM-1, Ramos and Hs 505.T were purchased from the American Type Culture Collection (ATCC) (Manassas, VA, USA). The FLT3-ITDexpressing line, MV4-11, was provided by Dr. Anthony Letai, Dana Farber Cancer Institute (DFCI), Boston, MA. The FLT3-ITD-expressing lines, MOLM-13 and MOLM14, were provided by Dr. Scott Armstrong, DFCI, Boston, MA. The wt FLT3-expressing AML line, NB4 (KRAS A18D), was obtained from Dr. Gary Gilliland. U937, HL-60, CMK, OCI-AML-2, OCI-AML-3, HEL, HT, Namalwa, NOMO-1, MEC-1 and MEC-2 were purchased from Cobioer Biosciences CO., LTD (Nanjing, China).

\section{Antibodies and immunoblotting}

The following antibodies were purchased from Cell Signaling Technology: Akt(\#4691), Phospho-Akt(Thr308) (\#4056), Phospho-Akt(Ser473)(\#4060), GAPDH, GSK3ß(\#9315), Phospho-GSK-3ß(\#9323), FoxO1(\#2880), Phospho-FoxO1 (Thr24)/FoxO3a(Thr32)/FoxO4(Thr28) (\#2599), PRAS40(\#2691), Phospho-PRAS40 (Thr246) (\#2997), 4E-BP1(\#9644), p70 S6K(\#2708), Phospho-p70 S6K (Thr389)(\#9234). SQSTM1/p62 (D5E2)(\#8025), LC3B(\#12513). PARP(\#9532), Caspase-3(\#9665), 
Phospho-p44/42 MAPK (Erk1/2) (Thr202/Tyr204) (\#4377), p44/42 MAPK (Erk1/2) (\#4695), PhosphoNF-KB P65 (Ser 536)(\#3033), NF-KB P65(\#4764). Lysophosphatidic Acid (\#sc-201053, Santa Cruz), Recombinant Human PDGF-BB (\#220-BB, R\&D), Recombinant Human C5a (Peprotech, \#300-70), goat anti-IgM (\#5C07615, Meridian). LC3B antibody (\#3868, CST). Tubulin antibody (\#8035, Santa Cruz). EEA1 antibody (\#610456, BD Bioscience) and LAMP1 antibody (\#24170, Abcam). Secondary antibodies, Alexa488-antimouse, Alexa594-anti-rabbit and Prolong gold mounting medium with DAPI were purchased from Invitrogen.

\section{ADP-Glo biochemical assay}

The activities of PI3K $\alpha, \operatorname{PI} 3 \mathrm{~K} \beta, \mathrm{PI} 3 \mathrm{~K} \delta, \operatorname{PI} 3 \mathrm{~K} \gamma$, PI3KC $2 \alpha$, PI3KC2 $\beta$, Vps34, PI4K $\alpha$ and PI4K $\beta$ were determined by using ADP-Glo assay, a fluorescencebased immunoassay that measures kinase activity in terms of the amount of ADP produced. A kinase titration was performed to determine the concentration. The amount of recombinant kinases was optimized to keep the reaction velocity within the linear range, to obtain an adequate difference between the resulting signals of sample in/ out the presence of enzyme. The optimized enzyme concentrations for evaluating the inhibitory activities of compounds were chosen as follows: $0.16 \mu \mathrm{g} / \mathrm{ml}, 6.0 \mu \mathrm{g} /$ $\mathrm{ml}, 1.0 \mu \mathrm{g} / \mathrm{ml}, 5.0 \mu \mathrm{g} / \mathrm{ml}, 5.0 \mu \mathrm{g} / \mathrm{ml}, 10.0 \mu \mathrm{g} / \mathrm{ml}, 1.2 \mu \mathrm{g} /$ $\mathrm{ml}, 1.2 \mu \mathrm{g} / \mathrm{ml}$ and $1.0 \mu \mathrm{g} / \mathrm{ml}$ for PI3K $\alpha$, PI3K $\beta$, PI3K $\delta$, PI $3 K \gamma$, PI3KC $2 \alpha$, PI3KC2 $\beta$, Vps34, PI4K $\alpha$ and PI4K $\beta$, respectively. The ATP concentration was optimized, $10 \mu \mathrm{M}$ ATP for PI3K $\alpha$ and PI3K $\beta$, and $50 \mu \mathrm{M}$ ATP for detection of the other seven kinases. The PI3K $\alpha$, PI3K $\beta$, PI3K $\delta$, $\mathrm{PI} 3 \mathrm{~K} \gamma, \mathrm{PI} 3 \mathrm{KC} 2 \alpha, \mathrm{PI} 3 \mathrm{KC} 2 \beta$ kinase reactions were carried out in $10 \mu \mathrm{l}$ volume in a 384-well plate in the kinase reaction buffer containing $50 \mathrm{mM}$ Hepes $\mathrm{pH}$ 7.5, $3 \mathrm{mM}$ $\mathrm{MgCl}_{2}, 1 \mathrm{mM}$ EGTA, $1 \mathrm{mM} \mathrm{NaCl}, 0.03 \%$ CHAPS and 2 $\mathrm{mM}$ DTT. In the case of VPS34, $2 \mathrm{mM} \mathrm{MnCl} \mathrm{Mn}_{2}$ and $2 \mathrm{mM}$ DTT were further added to the reaction buffer containing $50 \mathrm{mM}$ Hepes pH 7.5, $4 \mathrm{mM} \mathrm{MgCl}, 1 \mathrm{mM}$ EGTA and $0.1 \%$ CHAPS. For PI $4 \mathrm{~K} \alpha$ and PI $4 \mathrm{~K} \beta$, the reaction buffer consisting of $50 \mathrm{mM}$ Tris $\mathrm{pH} 7.5,5 \mathrm{mM} \mathrm{MgCl}, 0.5 \mathrm{mM}$ EGTA, $0.4 \%$ Triton X-100 and $2 \mathrm{mM}$ DTT was used. In all cases, $2.5 \mu \mathrm{l}$ of the respective kinase was added and the mixture was incubated at room temperature for 1 hour in the presence or absence of various concentrations of a given inhibitor. Each reaction was initiated by the addition of $2.5 \mu \mathrm{l}$ mixture of optimized concentrations of ATP and the substrate $(50 \mu \mathrm{M}$ PIP2:PS for PI3K $\alpha$, PI3K $\beta$, PI3K $\delta$ and PI3K $\gamma ; 100 \mu \mathrm{M}$ PI:PS for VPS34, PI4K $\alpha$ and PI4K $\beta$; $100 \mu \mathrm{M}$ PI for PI3KC $2 \alpha$ and PI3KC2 $\beta$, respectively). The assay was proceeded for 1 hour at $37{ }^{\circ} \mathrm{C}$ before addition of $5 \mu \mathrm{ADP}$-Glo reagent, and incubated for 40 min at room temperature. $10 \mu \mathrm{l}$ kinase detection reagent was dded and incubated for $30 \mathrm{~min}$ at room temperature, before the luminescence signal was read with an envision PerkinElmer plate reader.

\section{Kinase kinetic assay}

Kinetic analyses of $\mathrm{PI} 3 \mathrm{~K} \delta$ and $\mathrm{Vps} 34$ were performed using a luminometric kinase assay varying the concentration of ATP using the ADP-Glo reagents (Promega). The serially diluted PI3KD/V-IN-01 and PI3K $\delta(1.0 \mu \mathrm{g} / \mathrm{mL})$ were assayed in a reaction $(10 \mu \mathrm{L})$ containing $50 \mathrm{mM}$ Hepes $\mathrm{pH} 7.5,3 \mathrm{mM} \mathrm{MgCl} 2,1 \mathrm{mM}$ EGTA, $1 \mathrm{mM} \mathrm{NaCl}, 0.03 \%$ CHAPS, $2 \mathrm{mM}$ DTT, and Vps34 $(1.2 \mu \mathrm{g} / \mathrm{mL})$. In the case of Vps34, $2 \mathrm{mM} \mathrm{MnCl} 2$ and $2 \mathrm{mM}$ DTT were further added to the reaction buffer containing $50 \mathrm{mM}$ Hepes $\mathrm{pH} 7.5,4 \mathrm{mM} \mathrm{MgCl} 2,1 \mathrm{mM}$ EGTA and $0.1 \%$ CHAPS. After $60 \mathrm{~min}$ incubation at RT, varied concentrations of ATP and $0.1 \mathrm{mM}$ substrate (PIP2:PS for PI3K $\delta$, PI:PS for Vps34) were added and incubated for $60 \mathrm{~min}$ at $37^{\circ} \mathrm{C}$. The overall rate of reaction was determined as the slope of the decreasing phase of the reaction. Each data point was collected in duplicate and kinetic parameters were obtained using Prism 5.0 (GraphPad Software, San Diego, CA).

\section{PI3K isoforms cellular selectivity assay}

NIH-3T3(ATCC), NIH-3T3, RAW264.7 (ATCC) macrophages and Raji (ATCC) cells were seeded in a 6-well tissue culture plate and starved for 24 hours, then incubated with $\mathrm{PI} 3 \mathrm{KD} / \mathrm{V}-\mathrm{IN}-01$ at the desired concentrations for 1 hour followed by $20 \mathrm{ng} / \mathrm{ml}$ PDGFBB for $10 \mathrm{~min}, 5 \mu \mathrm{M}$ LPA for $10 \mathrm{~min}, 50 \mathrm{ng} / \mathrm{ml} \mathrm{c} 5$ a for 5 $\mathrm{min}$, and $1 \mu \mathrm{g} / \mathrm{ml}$ anti-IgM for $10 \mathrm{~min}$. Cells were lysed and AKT phosphorylation was determined by Western Blotting. Intensity of the bands was determined using ImageJ 1.42q (NIH, USA) and normalized to total AKT (loading control).

\section{Drug combination studies}

The cell lines, OCI-AML-2, MEC-2, Namalwa, and MV4-11, were grown in 96-well culture plates (3000/ well). A combination of the PI3K kinase inhibitor CAL101 with the VPS34 inhibitor VPS34-IN-1, was used to treat the cell lines. Cell proliferation were determined after treatment with the compounds for 72 hours. Cell viability was measured using the CellTiter-Glo assay (Promega, USA), data were normalized to control groups (DMSO) and represented by the mean of three independent measurements with a standard error $<20 \%$.

\section{Autophagy studies}

HeLa cells were treated with different concentrations of inhibitors for 16 hours. For all immunofluorescence experiments, cells were fixed in $-20{ }^{\circ} \mathrm{C}$ methanol for 5 minutes or $3.7 \%(\mathrm{v} / \mathrm{v})$ formaldehyde in phosphate- 
buffered saline (PBS) for 20 minutes. For LC3B staining, cells were fixed in $-20{ }^{\circ} \mathrm{C}$ methanol. For EEA1 and LAMP1 staining, cells were fixed in PBS+ formaldehyde. Cells were then permeabilized with TBSTx $(0.1 \%$ Triton X-100), blocked in AbDil (TBSTx $+2 \%$ BSA + $0.1 \% \mathrm{NaN} 3$ ), and probed with primary and secondary antibodies diluted in AbDil. Cells were rinsed thoroughly with TBSTx and mounted by anti-fade prolong Gold with DAPI. Images were taken using a Leica DMI4000B fluorescent microscope. All experiments were repeated at least three times). MEC-2, OCI-AML-2, OCI-AML-3 and MV4-11 cells were treated with serially-diluted PI3KD/VIN-01 for 6/12 hours. Hela cells were starved with EBSS for 2 hours, then treated with $25 \mu \mathrm{M}$ HCQ and serially diluted PI3KD/V-IN-01 for 1 hour. Cells were lysed in lysis buffer. P62, LC3B, and GAPDH antibodies were used for immunoblotting.

\section{Primary cells and primagraft cells}

Mononuclear cells were isolated from AML patients. Mononuclear cells were isolated by density gradient centrifugation through Ficoll-Plaque Plus (Amersham Pharmacia Biotech AB, Uppsala, Sweden) at $2000 \mathrm{rpm}$ for 30 minutes, followed by two washes in $1 \mathrm{X}$ PBS. Freeze-thawed cells were then cultured in liquid culture (DMEM, supplemented with 20\% FBS). All blood and bone marrow samples from AML patients were obtained through written consent under approval of the Dana Farber Cancer Institute Institutional Review Board. The ethics committees approved the consent procedure.

Peripheral blood mononuclear cells (PBMCs) from individuals with CLL were isolated by density centrifugation through Ficoll and frozen for each subject. Those subjects with low white counts whose CLL cell purity was expected to be $<85 \%$ underwent B cell isolation using RosetteSep. The protocol was approved by the Dana-Farber Harvard Cancer Center Institutional Review Board and all subjects signed written informed consent prior to participation.

\section{MV4-11 xenograft tumor model}

Six week old female nu/nu mice were purchased from the Shanghai Experimental Center, Chinese Science Academy (Shanghai). All animals were maintained in a specific pathogen-free facility and used according to the animal care regulations of Hefei Institutes of Physical Science Chinese Academy of Sciences, and all efforts were made to minimize animal suffering. To obtain an orthotopic xenograft of human mammary tumor in the mice, cells were harvested during exponential growth. 7 million MV4-11 cells in PBS were suspended in a 1:1 mixture with Matrigel (BD Biosciences) and injected into the subcutaneous space on the right flank of $\mathrm{nu} / \mathrm{nu}$ mice. Daily intraperitoneal injection was initiated when
MV4-11 tumors had reached a size of 200 to $400 \mathrm{~mm}^{3}$. Animals were then randomized into treatment groups of 5 mice each for efficacy studies. Compound PI3KD/ V-IN-01 was delivered daily in a HKI solution $(0.5 \%$ Methocellulose $/ 0.4 \%$ Tween 80 in $\mathrm{ddH}_{2} \mathrm{O}$ ) by orally gavages. A range of doses of compound PI3KD/V-IN-01 or its vehicle was administered, as indicated in the figure legends. Body weight and tumor growth were measured daily after PI3KD/V-IN-01 treatment. Tumor volumes were calculated as follows: tumor volume $\left(\mathrm{mm}^{3}\right)=\left[\left(\mathrm{W}^{2} \times \mathrm{L}\right) / 2\right]$ in which width (W) is defined as the smaller of the two measurements and length(L) is defined as the larger of the two measurements.

\section{TUNEL staining}

TUNEL staining was performed using the POD in Situ Cell Death Detection kit (Roche, USA). Sections were deparaffinized in xylene, rehydrated in decreasing concentrations of ethanol, then treated by nuclease free Proteinase $\mathrm{K}$ for $15 \mathrm{~min}$ at room temperature before endogenous peroxidase was blocked in $3 \% \mathrm{H}_{2} \mathrm{O}_{2}$ in methanol. Terminal deoxynucleotidyl transferase (TdT) in reaction buffer was applied to sections for $1 \mathrm{~h}$ at $37^{\circ} \mathrm{C}$. Following washes, the slides were covered by converterPOD solution for $30 \mathrm{~min}$ at $37^{\circ} \mathrm{C}$. Apoptotic cells were detected after incubation in the 3, 3'-diaminobenzidine (DAB) chromogen (Beyotime Biotechnology) for approximately $8 \mathrm{~min}$ and slides were counterstained with hematoxylin.

\section{Ki-67 staining}

For IHC demonstration of $\mathrm{Ki}-67$, tissue sections were quenched for endogenous peroxides and placed in an antigen retrieval solution (0.01M citrate buffer, $\mathrm{PH} 6.0)$ for $15 \mathrm{~min}$ in a microwave oven at $100^{\circ} \mathrm{C}$ at $600 \mathrm{~W}$. After incubation in the casein block, mouse MAb anti-Ki-67 (ZSGB-BIO) was applied to the sections at dilutions of 1:50. Incubations with primary antibodies lasted overnight at $4^{\circ} \mathrm{C}$. The secondary detection system was used to visualize antibody binding. Staining was developed with DAB; slides were counterstained with hematoxylin, dehydrated and mounted.

\section{HE staining}

HE staining was carried out as previously described. [15] First, the sections were hydrated and then the slide was dipped into a Coplin jar containing Mayer's hematoxylin and agitated for $30 \mathrm{sec}$. The slide was then rinsed in $\mathrm{H}_{2} \mathrm{O}$ for $1 \mathrm{~min}$. The slide was then stained with $1 \%$ eosin $\mathrm{Y}$ solution for $10-30 \mathrm{sec}$ with agitation. Subsequently, the sections were rinsed with two changes of $95 \%$ alcohol and two changes of $100 \%$ alcohol for 30 sec each. The alcohol was then extracted with two changes 
of xylene. Finally, one or two drops of mounting medium was added prior to covering with a cover slip.

\section{ACKNOWLEDGMENTS}

W. Wang, J. Liu and Q. Liu are supported by the grant of "Cross-disciplinary Collaborative Teams Program for Science, Technology and Innovation (2014-2016)" from Chinese Academy of Sciences. Z. Zhao is supported by Anhui Province Natural Science Foundation Annual Key Program (grant number: 1301023011). We want to thank China "Thousand Talents Program" support for Prof. Q. Liu and "Hundred Talents Program" of The Chinese Academy of Sciences support for Prof. J. Liu, and W. Wang. J.L. is also supported by theNational Program for Support of Top-notch Young Professionals. Q.L. is also supported by the CAS/SAFEA international partnership program for creative research teams.

\section{CONFLICTS OF INTEREST}

Dr. Shanchun Zhang is a shareholder of Hefei Cosource Medicine Technology Co. LTD.

\section{REFERENCES}

1. Chantry D, Vojtek A, Kashishian A, Holtzman DA, Wood C, Gray PW, Cooper JA, Hoekstra MF. p110delta, a novel phosphatidylinositol 3-kinase catalytic subunit that associates with p85 and is expressed predominantly in leukocytes. J Biol Chem. 1997; 272:19236-19241.

2. Fruman DA, Rommel C. PI3Kdelta inhibitors in cancer: rationale and serendipity merge in the clinic. Cancer Discov. 2011; 1:562-572.

3. Billottet C, Grandage VL, Gale RE, Quattropani A, Rommel C, Vanhaesebroeck B, Khwaja A. A selective inhibitor of the p110delta isoform of PI 3-kinase inhibits AML cell proliferation and survival and increases the cytotoxic effects of VP16. Oncogene. 2006; 25:6648-6659.

4. Bernal A, Pastore RD, Asgary Z, Keller SA, Cesarman E, Liou HC, Schattner EJ. Survival of leukemic B cells promoted by engagement of the antigen receptor. Blood. 2001; 98:3050-3057.

5. Brown JR, Byrd JC, Coutre SE, Benson DM, Flinn IW, Wagner-Johnston ND, Spurgeon SE, Kahl BS, Bello C, Webb HK, Johnson DM, Peterman S, Li D, Jahn TM, Lannutti BJ, Ulrich RG, et al. Idelalisib, an inhibitor of phosphatidylinositol 3-kinase p110delta, for relapsed/ refractory chronic lymphocytic leukemia. Blood. 2014; 123:3390-3397.

6. Vanhaesebroeck B, Khwaja A. PI3Kdelta inhibition hits a sensitive spot in B cell malignancies. Cancer cell. 2014; 25:269-271.

7. Fruman DA, Rommel C. PI3K and cancer: lessons, challenges and opportunities. Nat Rev Drug Discov. 2014; 13:140-156.
8. Shanware NP, Bray K, Abraham RT. The PI3K, metabolic, and autophagy networks: interactive partners in cellular health and disease. Annu Rev Pharmacol Toxicol. 2013; 53:89-106.

9. Mahoney E, Lucas DM, Gupta SV, Wagner AJ, Herman SE, Smith LL, Yeh YY, Andritsos L, Jones JA, Flynn JM, Blum KA, Zhang X, Lehman A, Kong H, Gurcan M, Grever MR, et al. ER stress and autophagy: new discoveries in the mechanism of action and drug resistance of the cyclin-dependent kinase inhibitor flavopiridol. Blood. 2012; 120:1262-1273.

10. Axe EL, Walker SA, Manifava M, Chandra P, Roderick HL, Habermann A, Griffiths G, Ktistakis NT. Autophagosome formation from membrane compartments enriched in phosphatidylinositol 3-phosphate and dynamically connected to the endoplasmic reticulum. J Cell Biol. 2008; 182:685-701.

11. Bago R, Malik N, Munson MJ, Prescott AR, Davies P, Sommer E, Shpiro N, Ward R, Cross D, Ganley IG, Alessi DR. Characterization of VPS34-IN1, a selective inhibitor of Vps34, reveals that the phosphatidylinositol 3-phosphatebinding SGK3 protein kinase is a downstream target of class III phosphoinositide 3-kinase. Biochem J. 2014; 463:413-427.

12. Ronan B, Flamand O, Vescovi L, Dureuil C, Durand L, Fassy F, Bachelot MF, Lamberton A, Mathieu M, Bertrand T, Marquette JP, El-Ahmad Y, Filoche-Romme B, Schio L, Garcia-Echeverria C, Goulaouic H, et al. A highly potent and selective Vps34 inhibitor alters vesicle trafficking and autophagy. Nat Chem Biol. 2014; 10:1013-1019.

13. Dowdle WE, Nyfeler B, Nagel J, Elling RA, Liu S, Triantafellow E, Menon S, Wang Z, Honda A, Pardee G, Cantwell J, Luu C, Cornella-Taracido I, Harrington E, Fekkes P, Lei H, et al. Selective VPS34 inhibitor blocks autophagy and uncovers a role for NCOA4 in ferritin degradation and iron homeostasis in vivo. Nat Cell Biol. 2014; 16:1069-1079.

14. Yu X, Long YC, Shen HM. Differential Regulatory Functions of Three Classes of Phosphatidylinositol and Phosphoinositide 3-Kinases in Autophagy. Autophagy. 2015:0.

15. Fischer AH, Jacobson KA, Rose J, Zeller R. Hematoxylin and eosin staining of tissue and cell sections. CSH Protoc. 2008; 2008:pdb prot4986.

16. Carpentier S, N'Kuli F, Grieco G, Van Der Smissen P, Janssens V, Emonard H, Bilanges B, Vanhaesebroeck B, Gaide Chevronnay HP, Pierreux CE, Tyteca D, Courtoy PJ. Class III phosphoinositide 3-kinase/VPS34 and dynamin are critical for apical endocytic recycling. Traffic. 2013; 14:933-948.

17. van Dam EM, Ten Broeke T, Jansen K, Spijkers P, Stoorvogel W. Endocytosed transferrin receptors recycle via distinct dynamin and phosphatidylinositol 3-kinasedependent pathways. The Journal of biological chemistry. 2002; 277:48876-48883. 